\title{
Patient-centred assessment of COPD in primary care: experience from a cross-sectional study of health-related quality of life in Europe
}

\section{*Paul W Jonesa, Guy Brusselle ${ }^{b}$, Roberto W Dal Negroc, Montse Ferrer,e, Peter Kardos ${ }^{f}$, Mark L Levy', Thierry Perez', Juan José Soler Cataluñai, Thys van der Molen', Lukasz Adamek', Norbert Banik'}

a Division of Clinical Science, St George's, University of London, London, UK

${ }^{\mathrm{b}}$ Department of Respiratory Medicine, Ghent University Hospital, Ghent, Belgium

Lung Department, Orlandi General Hospital, Bussolengo, Italy

'Health Services Research Unit, IMIM - Hospital del Mar Research Institute, Barcelona, Spain

e CIBER en Epidemiología y Salud Pública (CIBERESP), Spain

${ }^{\dagger}$ Respiratory Medicine, Maingau Hospital, Frankfurt am Main, Germany

${ }^{g}$ Allergy and Respiratory Research Group, Centre for Population Health Sciences, The University of Edinburgh, Edinburgh, UK

h Pulmonology Department, Lille University Hospital, Lille, France

' Pneumology Unit, Requena General Hospital, Valencia, Spain

'University Medical Centre Groningen, The Netherlands

${ }^{k}$ Respiratory Centre of Excellence, GlaxoSmithKline, Uxbridge, UK

' Biostatistics and Epidemiology, GlaxoSmithKline, Munich, Germany

Original submission 7th December 2011; resubmitted 15th December 2011; revised version received 21st March 2012; final revision

31st May 2012; accepted 3rd June 2012; online 10th August 2012

\begin{abstract}
Background: Most patients with chronic obstructive pulmonary disease (COPD) in Europe are treated in primary care, but perceptions on what guides primary care physicians (PCPS) in managing patients are lacking.

Aims: To describe factors associated with the assessment by PCPs of COPD severity and those associated with impaired health status, as assessed by patient-reported outcomes.

Methods: This cross-sectional study evaluated health-related quality of life (HRQL) in 2,294 COPD patients from five European countries. The severity of COPD was clinically judged by the PCPS and GOLD stage severity was calculated using spirometry data.

Results: PCPs' categories of severity reflected a wider range of HRQL scores (St George's Respiratory Questionnaire (SGRQ) total score: mild 30.3; moderate 41.7; severe 55.0; very severe 66.1) than GOLD severity grading (Stage I 38.2; Stage II 41.1; Stage III 49.9; Stage IV 58.5). Multiple ordinal logistic regression models showed that factors most closely related to PCP-rated COPD severity were Medical Research Council (MRC) dyspnoea grade, forced expiratory volume in 1 second $\left(F V_{1}\right)$ percent predicted, HRQL score (either SGRQ or COPD Assessment Test $(C A T)$ ), and previous hospitalisations (model generalised $R^{2}=0.45$ or 0.44 (SQRQ or CAT in model, respectively); all factors $p<0.0001$ ). Factors with the highest association with HRQL scores (SGRQ or CAT) were MRC dyspnoea grade, COPD severity (PCP-rated), sputum production, and number of co-morbidities (model $\mathrm{R}^{2}=0.46$ or 0.37 (SQRQ or CAT in multiple linear regression model, respectively); all factors $p<0.0001$ ).

Conclusions: PCPs successfully graded COPD severity clinically and appeared to have greater discriminative power for assessing severity in COPD than FEV 1 -based staging. Their more holistic approach appeared to reflect the patients' HRQL rating and was consistent across five European countries.

(C) 2012 Primary Care Respiratory Society UK. All rights reserved.

PW Jones et al. Prim Care Respir J 2012; 21(3): 329-336

http://dx.doi.org/10.4104/pcrj.2012.00065
\end{abstract}

Keywords COPD, health-related quality of life, primary care, Europe, cross-sectional, HEED

* Corresponding author: Professor PW Jones, Division of Clinical Science, St George's, University of London, London SW17 ORE, UK. E-mail: pjones@sghms.ac.uk 


\section{Introduction}

Chronic obstructive pulmonary disease (COPD) is a leading cause of morbidity and mortality worldwide and its prevalence is predicted to increase due to the continued use of tobacco and because many more people - especially those from developing countries - are living into the COPD age range. ${ }^{1}$ The majority of patients with COPD are managed in primary care, ${ }^{2}$ and this is reflected in recent attempts to target guidelines at primary care physicians (PCPs), ${ }^{2,3}$ Despite such guidelines, COPD remains under-diagnosed ${ }^{4}$ and the prevalence of COPD is often higher than is recognised in official statistics. ${ }^{5-7}$

Spirometry remains the standard method for confirming a clinical diagnosis of COPD and for grading COPD severity ${ }^{2,8,9}$ and, although robust and inexpensive spirometers are now available, it still appears to be a barrier in diagnosing and managing COPD in primary care. ${ }^{10} \mathrm{~A}$ lack of correlation between post-bronchodilator forced expiratory volume in 1 second $\left(\mathrm{FEV}_{1}\right)$ and other outcomes such as dyspnoea, exercise testing, and health-related quality of life (HRQL) has also been shown, ${ }^{11-13}$ and it is now recognised that FEV 1 measurements alone do not represent the multi-component nature of COPD. ${ }^{11,14}$

A recent review of epidemiological surveys of COPD characteristics shows varying results across countries ${ }^{15}$ and the authors concluded that accurate reporting of COPD epidemiological parameters is important for choices of preventive measures, interventions, and patient management in various healthcare systems. Research initiatives such as the BOLD ${ }^{16}$ and PLATINO ${ }^{17}$ studies have helped to standardise the methods of data collection and comparability across countries, but epidemiological data from a primary care setting - and, specifically, data on what influences PCPS in managing COPD patients - are still lacking.

The health-related quality of life in COPD in Europe study (HEED) was a cross-sectional observational study undertaken to provide data on the HRQL of a sample of COPD patients from primary care settings across Europe. Results from this study for a population who fulfilled Global Initiative for Chronic Obstructive Lung Disease (GOLD) criteria have been published previously and demonstrated marked health status impairment in COPD patients of all severities, even those with mild disease. ${ }^{18}$

The main aim of this paper is to describe the factors associated with the assessment by PCPs of COPD severity. The complete HEED population, who had a confirmed PCP diagnosis of COPD without applying strict spirometry criteria, was evaluated. This real-life approach was intended to reflect how PCPs manage their COPD patients in everyday practice. An additional aim is to describe any factors associated with impaired health status as assessed by patient-reported outcomes.

\section{Methods}

Full details of the HEED design and entry requirements have been published previously. ${ }^{18}$ In brief, patients with PCP-diagnosed COPD attending a PCP for any reason were invited to participate in this cross-sectional single-visit observational study; patients were recruited between November 2008 and May 2009. This additional analysis evaluated patient data from five European countries
Figure 1. Patient flow through the European HRQL survey. $\mathrm{COPD}=$ chronic obstructive pulmonary disease; $\mathrm{PCP}=$ primary care physician

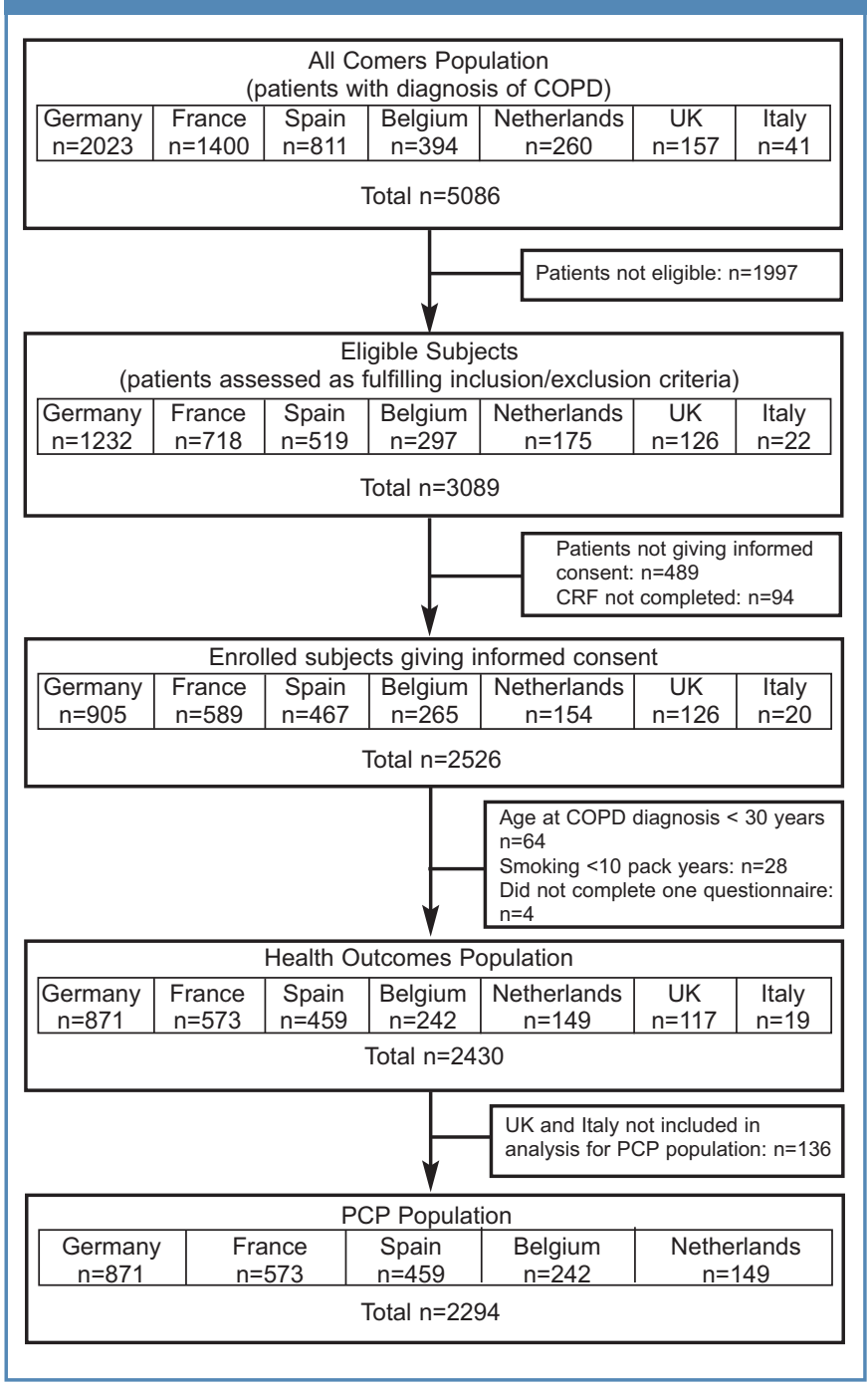

(Belgium, France, Germany, the Netherlands, and Spain). In order to exclude any potential biases in the exploratory analyses performed for this paper in comparison with the descriptive statistics used in the primary paper, patient data from Italy and the UK were excluded due to low patient numbers (Italy: $\mathrm{N}=19 ; \mathrm{UK}: \mathrm{N}=117$; Figure 1). The UK also used a specific patient identification process which differed from other countries and accounted for the recruitment of 39 of their patients.

Patients completed four HRQL questionnaires at the study visit: St George's Respiratory Questionnaire-COPD specific (SGRQ-C) (score range 0 (no impairment) to 100 (worst possible)); $;^{19}$ generic Short Form Health Survey (SF-12) (score range 0 (worst) to 100 (best)):;0 COPD Assessment Test (CAT) (score range 0 (best) to 40 (worst) $)_{i}^{21}$ and Functional Assessment of Chronic Illness Therapy (FACIT) fatigue scale (score range 0 (most fatigue) to 52 (least fatigue)). ${ }^{22}$ Breathlessness scores (MRC dyspnoea scale), ${ }^{23}$ symptoms, lung function parameters, numbers of co-morbidities, and details of 
exacerbations were also recorded. An exacerbation was defined as a worsening of symptoms that required oral corticosteroids and/or antibiotics and/or hospitalisation. Severity of COPD was judged on clinical grounds by the PCP as mild, moderate, severe, or very severe. The patient case report form was designed so that the PCP severity assessment was completed first, followed by lung function, MRC dyspnoea scale and, lastly, patient completion of the HRQL questionnaires in order to try to minimise the influence of any of these tools on severity judgement by the PCP. Spirometry had to be performed within 6 months before study entry or during the single study visit. The nature of the HRQL instruments applied made it impossible to guess the final score based on the questionnaire items themselves. Moreover, the final CAT items were derived when the study was finished and, consequently, individual HRQL ratings could not have reasonably influenced the severity rating by the PCP. However, the PCPs would have known their patients' medical history and may have seen previous results for $\mathrm{FEV}_{1}$ in patients' medical records. GOLD stage severity was calculated retrospectively using lung function data.

\section{Statistical analysis}

Sample size calculations for this study have been presented elsewhere. ${ }^{18}$ Descriptive statistics, analysed using Statistical Analysis Systems version 9.1.3 software (SAS Inc, Cary, USA), were used to report demographic and baseline characteristics and distribution of quality of life questionnaire scores for both the Health Outcomes Population (defined as all subjects who completed at least one questionnaire) and subgroups split by country, sex, age, COPD severity, COPD status (stable disease vs. exacerbation), COPD severity, and number of co-morbidities.

Multiple ordinal logistic regression analyses were performed to examine the relationship between PCP-rated COPD severity level and a number of demographic and clinical variables (age, country, body mass index, number of exacerbations requiring hospitalisation in the past 6 months, symptoms (cough and sputum), current exacerbation status, $\mathrm{FEV}_{1}$ percentage predicted and $\mathrm{FEV}_{1} / \mathrm{FVC}$ ratio, number of co-morbidities, MRC dyspnoea grade and, alternatively, SGRQ (total score) or CAT score). Stepwise variable selection was performed in order to obtain a final model with the most influential variables explaining the PCP-clinically rated COPD severity as the dependent variable. In order to give an impression about the goodness-of-fit of the final ordinal logistic regression models, generalised Cox-Snell model $R^{2}$ values were reported.

Likewise, multiple linear regression models with stepwise variable selection were performed including demographic and clinical variables (as specified above for the logistic regression models but including PCP-rated COPD severity as independent variables) in order to obtain a set of variables with the highest association with the two alternatively modelled dependent variables SGRQ and CAT.

In all models, country was always used as a factor in order to explore how far the findings were country-specific or could be generalised to the five countries based on the data of this study. The threshold for entering variables into the model or removing them from it was set at the 0.05 level.

\section{Results}

Patient demographic and clinical characteristics

A total of 5,086 patients presented at their PCP practices with a diagnosis of COPD, of whom 2,526 were eligible and gave their informed consent. The additional analyses presented here include data from 2,294 patients (PCP population; see Figure 1).

Patient characteristics for the PCP population presented by PCPrated severity are shown in Table 1. Approximately two-thirds of patients were male with a mean age of 64 years and a mean duration of COPD of 9 years. Mean FEV 1 was $1.6 \mathrm{~L}$ (FEV $159 \%$ predicted) and the majority of patients were experiencing symptoms of cough, sputum production, and breathlessness. Reported comorbidities were: hypertension 54\%, hypercholesterolaemia $42 \%$, sleep disorder $27 \%$, osteoarthritis $26 \%$, heartburn $22 \%$, diabetes $19 \%$, depression $18 \%$, anxiety $16 \%$, arrhythmia $11 \%$, and heart failure $10 \%$.

Mean duration of COPD, smoking pack-years, COPD symptoms, and the mean number of exacerbations (requiring treatment and/or hospitalisation) in the previous 6 months increased with increasing COPD severity. Patients with more severe disease also had a lower $\mathrm{FEV}_{1}$ and a more severe rating on the MRC dyspnoea scale (Table 1).

\section{Correlation between PCP-rated and GOLD-based severity rating}

The association between PCP-rated COPD severity and severity by spirometry-based GOLD classification criteria is presented in Figure 2. There was a modest agreement between the two types of classification (Spearman's rank correlation coefficient $0.464,95 \% \mathrm{Cl}$ 0.428 to 0.499).

\section{Factors related to PCP-rated COPD severity}

The multiple ordinal logistic regression modelling showed that the five variables which best explained PCP severity rating were MRC dyspnoea grade, FEV 1 percent predicted, total SGRQ score or CAT score (whichever was in the model), history of hospitalisations due to exacerbations in the last 6 months, and $\mathrm{FEV}_{1} / \mathrm{FVC}$ ratio

\section{Figure 2. Primary care physician (PCP)-rated severity} versus Global Initiative for Chronic Obstructive Lung Disease (GOLD) classification. COPD=chronic obstructive pulmonary disease

GOLD classification: $\square$ Stage I $\square$ Stage II $\square$ Stage III $\square$ Stage IV

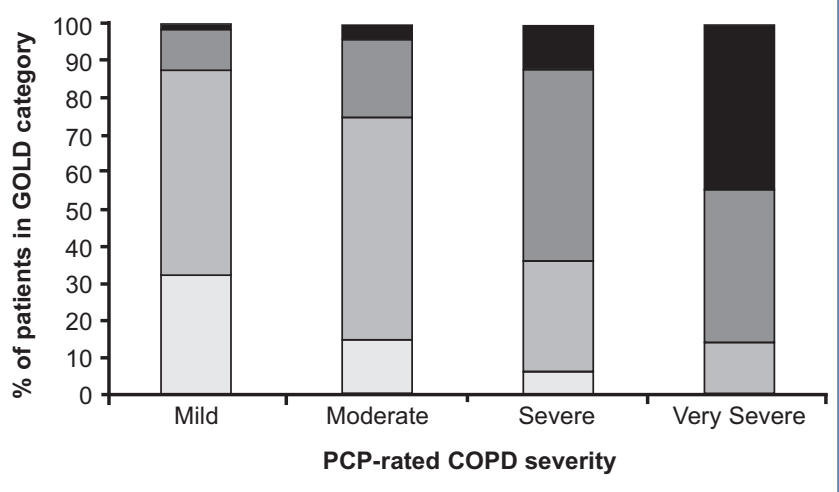


Table 1. Demographic and clinical characteristics

\begin{tabular}{|c|c|c|c|c|c|}
\hline & $\begin{array}{l}\text { PCP-ratec } \\
\text { Mild }\end{array}$ & $\begin{array}{l}\text { Mrity } \\
\text { Moderate }\end{array}$ & Severe & Very severe & $\begin{array}{l}\text { PCP population } \\
(\mathrm{n}=2,294)\end{array}$ \\
\hline $\mathrm{N}$ (\% of total population) & $424(18.5)$ & $1174(51.2)$ & $573(25.0)$ & $123(5.3)$ & \\
\hline Male sex, n (\%) & $287(67.7)$ & $808(68.8)$ & $405(70.7)$ & $90(73.2)$ & $1,590(69.3)$ \\
\hline Age (years), mean (SD) & $63.1(10.4)$ & $64.0(10.2)$ & $65.5(9.3)$ & $66.9(8.6)$ & $64.4(10.0)$ \\
\hline Duration COPD (years), mean (SD) & $6.7(5.9)$ & $8.8(6.7)$ & $11.1(7.1)$ & $13.9(8.3)$ & $9.2(7.0)$ \\
\hline Pack-years, mean (SD) & $35.5(25.3)$ & $38.1(23.5)$ & $42.4(24.3)$ & $45.9(29.9)$ & $39.1(24.6)$ \\
\hline Current smoker, n (\%) & $202(47.6)$ & $574(48.9)$ & $229(40.0)$ & $30(24.4)$ & $1,035(45.1)$ \\
\hline Number of co-morbidities, mean (SD) & $1.9(1.5)$ & $2.1(1.7)$ & $2.1(1.7)$ & $2.3(1.8)$ & $2.1(1.7)$ \\
\hline Number of cardiovascular co-morbidities, mean (SD) & $0.8(0.9)$ & $0.9(1.0)$ & $1.1(1.1)$ & $1.0(1.1)$ & $0.9(1.0)$ \\
\hline $\begin{array}{l}\text { Disease status on study day, } \mathrm{n}(\%) \\
\text { Stable disease } \\
\text { Exacerbation }\end{array}$ & $\begin{array}{l}399(94.1) \\
25(5.9)\end{array}$ & $\begin{array}{l}1027(87.5) \\
147(12.5)\end{array}$ & $\begin{array}{l}453(79.1) \\
120(20.9)\end{array}$ & $\begin{array}{l}92(74.8) \\
31(25.2)\end{array}$ & $\begin{array}{l}1,971(85.9) \\
323(14.1)\end{array}$ \\
\hline $\begin{array}{l}\text { Exacerbations in last } 6 \text { months, } \mathrm{n}(\%) \text {, requiring } \\
\text { Antibiotics } \\
\text { Oral corticosteroids } \\
\text { Hospitalisation }\end{array}$ & $\begin{array}{l}154(36.3) \\
74(17.5) \\
10(2.4) \\
\end{array}$ & $\begin{array}{l}652(55.5) \\
368(31.3) \\
53(4.5) \\
\end{array}$ & $\begin{array}{l}389(67.9) \\
284(49.6) \\
1144(19.9)\end{array}$ & $\begin{array}{l}85(69.1) \\
69(56.1) \\
38(30.9)\end{array}$ & $\begin{array}{l}1,280(55.8) \\
795(34.6) \\
215(9.4)\end{array}$ \\
\hline $\begin{array}{l}\text { COPD symptoms on study day, n (\%) } \\
\text { Cough } \\
\text { Sputum } \\
\text { Dyspnoea }\end{array}$ & $\begin{array}{l}283(66.7) \\
200(47.2) \\
179(42.2) \\
\end{array}$ & $\begin{array}{l}927(79.0) \\
779(66.4) \\
819(69.8) \\
\end{array}$ & $\begin{array}{l}481(83.9) \\
460(80.3) \\
525(91.6) \\
\end{array}$ & $\begin{array}{l}104(84.6) \\
95(77.2) \\
122(99.2) \\
\end{array}$ & $\begin{array}{l}1,795(78.2) \\
1,534(66.9) \\
1,645(71.7)\end{array}$ \\
\hline $\begin{array}{l}\text { Lung function, mean (SD) } \\
\text { FEV } V_{1}(\mathrm{~L}) \\
\mathrm{FEV}_{1} \% \text { of predicted }\end{array}$ & $\begin{array}{l}2.0(0.6) \\
72.5(20.3) \\
\end{array}$ & $\begin{array}{l}1.7(0.6) \\
62.2(18.7) \\
\end{array}$ & $\begin{array}{l}1.3(0.5) \\
48.4(18.5) \\
\end{array}$ & $\begin{array}{l}0.9(0.3) \\
34.6(13.6) \\
\end{array}$ & $\begin{array}{l}1.6(0.6) \\
59.0(21.1) \\
\end{array}$ \\
\hline $\begin{array}{l}\text { MRC dyspnoea scale*, n (\%) } \\
1 \\
2 \\
3 \\
4 \\
5\end{array}$ & $\begin{array}{l}189(44.6) \\
180(42.5) \\
43(10.1) \\
11(2.6) \\
1(0.2)\end{array}$ & $\begin{array}{l}234(19.9) \\
524(44.6) \\
303(25.8) \\
98(8.3) \\
13(1.1)\end{array}$ & $\begin{array}{l}41(7.2) \\
161(28.1) \\
167(29.1) \\
161(28.1) \\
41(7.2)\end{array}$ & $\begin{array}{l}4(3.2) \\
10(8.1) \\
16(13.0) \\
47(38.2) \\
45(36.6)\end{array}$ & $\begin{array}{l}468(20.4) \\
875(38.1) \\
529(23.1) \\
317(13.8) \\
100(4.4)\end{array}$ \\
\hline
\end{tabular}

*MRC scale: 1=only breathless with strenuous exercise; $2=$ breathless when hurrying on level or up a slight hill; $3=$ walk slower than people of same age on the level due to breathlessness or stop for breath when walking on level at own pace; $4=$ stop for breath after walking 100 yards or a few minutes on the level; $5=$ too breathless to leave house or breathless when dressing

$\mathrm{COPD}=$ chronic obstructive pulmonary disease; $\mathrm{FEV} \mathrm{V}_{1}=$ forced expiratory volume in 1 second; $\mathrm{MRC}=$ Medical Research $\mathrm{Council} ; \mathrm{PCP}=$ primary care physician.

(generalised model $\mathrm{R}^{2}=0.45$ (SQRQ but not CAT in model) and $\mathrm{R}^{2}$ $=0.44$ (CAT but not SGRQ in model) (Table 2). When the same type of model was applied but with exclusion of HRQL scores from the model, the variables most closely related to PCP severity rating were MRC dyspnoea grade, FEV 1 percent predicted, history of hospitalisations in the last 6 months, sputum production, and $\mathrm{FEV}_{1} / \mathrm{FVC}$ ratio (model $\mathrm{R}^{2}=0.42$ ).

The five variables in the model which best explained the PCPrated COPD severity occurred consistently across all five countries because 'country' did not emerge as a significant factor in the stepwise logistic regression models.

\section{HRQL scores}

HRQL scores presented by PCP-rated severity and by GOLD classification are summarised in Table 3 and showed marked impairment in HRQL across all severities of COPD, regardless of the rating categorisation. There was considerable heterogeneity in impairment among patients. PCPs' categories of severity reflected a wider range of health status scores than GOLD severity grading based on $\mathrm{FEV}_{1}$, and these results were consistent across all instruments (Table 3, Figure 3). Differences in scores between PCPrated severity groups exceeded the minimum clinically important difference (MCID) for SGRQ (MCID=4), SF-12 (MCID=3-3.5) and FACIT (MCID=3-4) scores. When COPD severity was graded according to the GOLD classification criteria $\left(F E V_{1}\right)$, HRQL scores did not exceed the MCID between GOLD stages I and II but showed significant worsening between stages II-III and III-IV.

\section{Factors related to HRQL scores (SGRQ and CAT)]}

The five variables with the highest association with the total SGRQ and CAT scores are shown in Table 4. The first four variables were identical for both HRQL scores: MRC dyspnoea grade, PCP-rated severity, sputum production, and number of co-morbidities. The fifth variable showing a strong association with the SGRQ was disease status (stable vs. exacerbation) and with the CAT it was cough. 


\begin{tabular}{|c|c|c|c|}
\hline Step & Variable entered* & $\begin{array}{l}\text { Chi-square } \\
\text { score }\end{array}$ & $\mathrm{p}$ valuet \\
\hline \multicolumn{4}{|c|}{ A: Including SGRQ in the model, not CAT } \\
\hline 1 & MRC dyspnoea scale score & 473.3 & $<0.0001$ \\
\hline 2 & $\mathrm{FEV}_{1}$ percent predicted & 259.2 & $<0.0001$ \\
\hline 3 & SGRQ total score & 104.7 & $<0.0001$ \\
\hline 4 & $\begin{array}{l}\text { Number of hospitalisations due to } \\
\text { exacerbations in past } 6 \text { months }\end{array}$ & 24.8 & $<0.0001$ \\
\hline 5 & $\mathrm{FEV}_{1} / \mathrm{FVC}$ ratio & 20.3 & 0.0001 \\
\hline \multicolumn{4}{|c|}{ B: Including CAT in the model, not SGRQ } \\
\hline 1 & MRC dyspnoea scale score & 516.3 & $<0.0001$ \\
\hline 2 & $\mathrm{FEV}_{1}$ percent predicted & 290.8 & $<0.0001$ \\
\hline 3 & CAT total score & 59.2 & $<0.0001$ \\
\hline 4 & $\begin{array}{l}\text { Number of hospitalisations due to } \\
\text { exacerbations in past } 6 \text { months }\end{array}$ & 29.3 & $<0.0001$ \\
\hline 5 & $\mathrm{FEV}_{1} / \mathrm{FVC}$ ratio & 20.7 & 0.0001 \\
\hline \multicolumn{4}{|c|}{$\begin{array}{l}\text { CAT=COPD Assessment Test; FEV }{ }_{1}=\text { forced expiratory volume in } 1 \\
\text { second; FVC=forced vital capacity; } M R C=\text { modified Medical Research } \\
\text { Council; SGRQ=St George's Respiratory Questionnaire. }\end{array}$} \\
\hline
\end{tabular}

The five variables in the models with the highest associations with the HRQL scores (SGRQ or CAT) occurred consistently across all five countries because 'country' was never identified in the stepwise variable selection processes as a significant factor.

\section{Discussion}

\section{Main findings}

This large scale study in five European countries showed that HRQL in patients with COPD is very poor across all levels of PCP-rated severity. It also provides insights into the factors that PCPs use when assessing
Table 3. Health-related quality of life (HRQL) scores by PCP-rated severity and by GOLD classification

\begin{tabular}{|c|c|c|c|c|}
\hline \multirow{2}{*}{$\begin{array}{l}\text { HRQL score } \\
\text { Mean (SD) }\end{array}$} & \multicolumn{4}{|c|}{ PCP-rated severity } \\
\hline & $\begin{array}{l}\text { Mild } \\
(n=424)\end{array}$ & $\begin{array}{l}\text { Moderate } \\
(n=1174)\end{array}$ & \begin{tabular}{|l} 
Severe \\
$(n=573)$
\end{tabular} & $\begin{array}{l}\text { Very severe } \\
(n=123)\end{array}$ \\
\hline \multicolumn{5}{|l|}{ SGRQ* } \\
\hline Total score & $30.3(15.7)$ & $41.7(17.1)$ & $55.0(17.4)$ & $66.1(17.0)$ \\
\hline CATt & $12.7(7.2)$ & $16.8(7.7)$ & $21.4(8.0)$ & $24.5(9.2)$ \\
\hline \multicolumn{5}{|l|}{ SF-12‡ } \\
\hline PCS & $42.9(8.7)$ & $39.0(8.4)$ & $33.6(8.5)$ & $29.5(7.0)$ \\
\hline MCS & $50.5(10.6)$ & $47.6(11.4)$ & $44.6(12.0)$ & 40.8 (13.9) \\
\hline \multirow[t]{3}{*}{ FACIT-F§ } & $40.5(8.9)$ & $36.1(10.6)$ & $29.7(11.8)$ & $24.2(13.0)$ \\
\hline & \multicolumn{4}{|c|}{ GOLD classification } \\
\hline & $\begin{array}{l} \\
(n=337)\end{array}$ & $\begin{array}{l}\text { II } \\
(n=1059)\end{array}$ & \begin{tabular}{|l|l} 
III \\
$(n=606)$
\end{tabular} & \begin{tabular}{|l|l} 
IV \\
$(n=153)$
\end{tabular} \\
\hline \multicolumn{5}{|l|}{ SGRQ* } \\
\hline Total score & $38.2(19.4)$ & $41.1(18.3)$ & 49.9 (18.6) & $58.5(18.2)$ \\
\hline CATt & $15.9(8.6)$ & $16.5(8.0)$ & $19.2(8.1)$ & $22.4(9.0)$ \\
\hline \multicolumn{5}{|l|}{ SF-12‡ } \\
\hline PCS & $40.0(9.0)$ & $39.2(8.8)$ & $35.7(8.8)$ & $31.7(8.8)$ \\
\hline MCS & $47.9(11.8)$ & $47.5(11.3)$ & $47.1(12.0)$ & 43.6 (12.9) \\
\hline FACIT-F§ & $36.6(10.8)$ & $36.1(10.9)$ & $32.6(12.2)$ & $28.6(12.5)$ \\
\hline
\end{tabular}

*SGRQ total score: a lower score represents a better quality of life; tCAT score: a lower score represents a better quality of life. \#SF-12 scores: a higher score represents a better quality of life; §FACIT fatigue scores: higher score indicates less fatigue.

CAT=COPD Assessment Test; FACIT-F= Functional Assessment of Chronic Illness Therapy (FACIT) fatigue scale; GOLD=Global Initiative for Chronic Obstructive Lung Disease; $\mathrm{MCS}=$ Mental component score; $\mathrm{PCP}=$ primary care physician; PCS=Physical component score; SF-12=Short Form Health Survey; SGRQ=St George's Respiratory Questionnaire.

\section{Figure 3. (A) SGRQ score and (B) CAT score by PCP-rated COPD severity and GOLD staging. CAT=COPD Assessment Test; COPD=chronic obstructive pulmonary disease; GOLD=Global Initiative for Chronic Obstructive Lung Disease; $\mathrm{PCP}=$ primary care physician; SGRQ=St George's Respiratory Questionnaire}

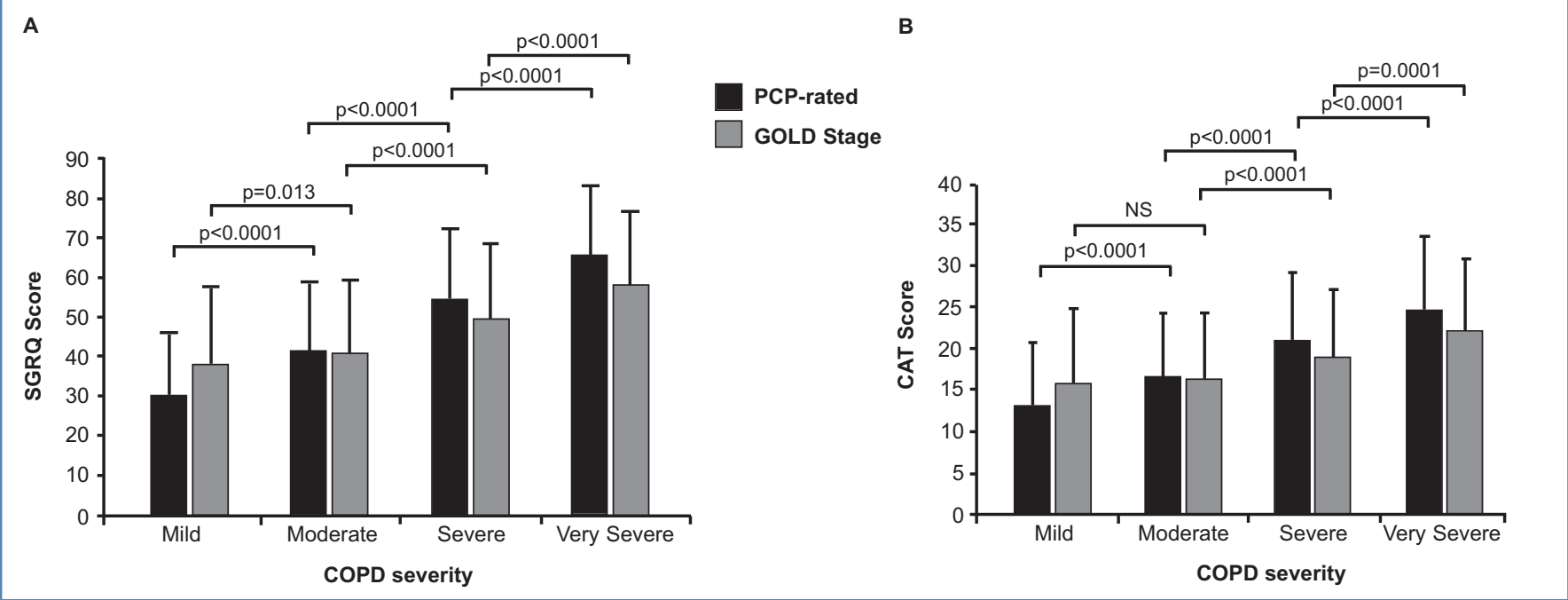




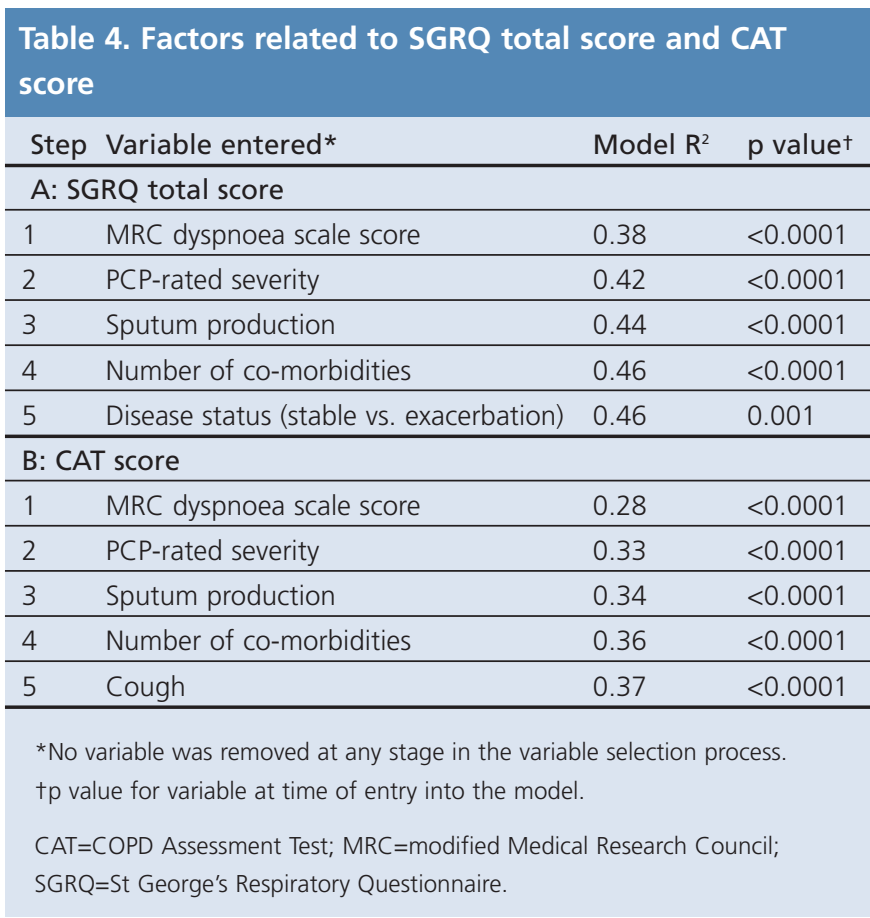

COPD patients in routine clinical practice. Their categories of severity reflected a wider range of health status scores than GOLD severity grading based on FEV 1 . For example, the health status scores of patients did not differ significantly between GOLD stages I and ॥ whereas, for PCP-rated COPD severity, there were clinically significant differences in HRQL scores between all stages of severity. This also explains why PCP-rated COPD severity and the spirometry-based GOLD classification criteria were discordant. The results suggest that PCPs take a number of additional factors into account when judging COPD severity including breathlessness, hospitalisations and an impression of overall health status, in addition to FEV 1 . Therefore, an important message from this study is that, on average, PCPs were able to assess severity successfully in COPD patients and suggests that PCPs' estimates of severity have greater discriminative power for assessing severity in COPD than FEV 1 -based staging.

The modelling results for the SGRQ and CAT fit these findings for PCP-rated disease severity. When modelling the variables that best explained the HRQL scores, the PCP rating of severity emerged as the second strongest factor for both scores. This also supports the notion that PCPs in their global assessment are in relatively close agreement with their patients' assessment made through questionnaires such as the SGRQ-C and CAT. In addition, PCPS performed their evaluation of patient severity without knowledge of the SGRQ and CAT final scores. The absence of 'country' as a significant factor in these models would suggest that these findings are generalisable across the five European countries involved. This indicates that assessment of COPD patients in primary care within these countries has some important aspects in common despite the different health systems, patient populations, and somewhat different cultures.

The findings for the CAT questionnaire were consistent with the other validated health status instruments. The multiple logistic regression analyses showed that the CAT behaved in a very similar way to the SGRQ, the four variables most influencing a given HRQL score being identical for the two instruments (MRC dyspnoea grade, PCP-rated severity, sputum production, and number of comorbidities). CAT and SGRQ scores have also been shown to be strongly correlated. ${ }^{24}$ These modelling results support the relevance of both questionnaires and MRC as measures of severity used for assessing COPD. They also suggest that the CAT questionnaire could be a useful alternative to the SGRQ since it is much shorter and easier to use in clinical practice. ${ }^{24}$

\section{Strengths and limitations of this study}

The strengths of this study are that it was a large-scale survey that assessed HRQL in COPD patients in a primary care setting using both generic and disease-specific questionnaires. Although for some patients the diagnosis of COPD could not be confirmed by spirometry, this study did represent diagnosed COPD patients as they are seen in everyday PCP practices.

The study could not address the health status of patients with undiagnosed disease; however, a recent population-based survey reported impaired HRQL (raised SGRQ) in patients with undiagnosed COPD compared with healthy subjects, but less impairment in this group compared with diagnosed COPD patients. ${ }^{25}$ For mild patients who remain undiagnosed, some argue that early detection and prevention - particularly in introducing smoking cessation programmes - may offer a better long-term prognosi ${ }^{26,27}$ although other studies have not confirmed this. ${ }^{28,29}$ Also, although only five European countries were represented in this analysis and there were some inter-country variations in demographic factors, the relationship between HRQL impairment and PCP-rated severity showed very similar patterns across countries, suggesting that these data may be representative at the European level. This requires confirmation in further studies, with representation in Northern and Eastern Europe.

While this study shows that PCPs are good at assessing the severity of COPD in their patients, across all severities of COPD antibiotics were used more frequently than oral corticosteroids for treating exacerbations which is not in line with guidelines for managing COPD exacerbations ${ }^{2}$ or the evidence in the literature which questions the effectiveness of treating outpatient exacerbations with antibiotics. ${ }^{30,31}$ However, the collection of exacerbations in this study was based on retrospective assessments and relied partly on patient recall and therefore does not allow for further speculation based on these data.

\section{Interpretation of findings in relation to previously published work}

In a previous report from this study we showed that SGRQ scores were already markedly higher in patients with mild COPD compared with healthy controls (upper limit of normal 7 units). ${ }^{18,32}$ The wider PCP population reported here showed very similar baseline and demographic characteristics to patients fulfilling the stricter GOLD criteria described in the previous HRQL in Europe publication. ${ }^{18}$ The characteristics of our population are in broad agreement with those reported in the EPIDEPOC study, a large observational study in primary care, specifically with respect to mean age, proportion of males/females, smoking history, associated co-morbidities, and mean 
percent predicted FEV $1 .{ }^{33,34}$ Compared with the EPISCAN study, our patients were older, had a greater smoking pack-year history and a lower FEV 1 ; however, only $5.3 \%$ of subjects in the EPISCAN study had had a previous clinical diagnosis of COPD. ${ }^{25}$ Comparisons of epidemiological characteristics with other studies are limited due to the variability in COPD definition, severity scales, methodologies and target populations, as has recently been highlighted by Atsou and colleagues. ${ }^{15} \mathrm{~A}$ comparison of COPD severity staging based on spirometry between our study and other published findings ${ }^{15}$ showed general agreement in the proportion of patients classified as having moderate Stage II COPD (approximately 50\% of the population for all studies), but we reported a smaller proportion of patients classified as Stage I (mild) compared with other studies (15.6\% vs. range $20-31 \%$ ) and a larger proportion classified as Stage III (severe) (28.1\% vs. range 15-22\%). The most likely reason for our population having slightly more severe disease is differences in methodologies. Bednarek and colleagues invited all patients aged $>40$ to be screened for their study, thus capturing patients without a previous diagnosis of COPD (i.e. those more likely to have mild (OPD), unlike our study which only included patients with diagnosed COPD. ${ }^{35}$ Similarly, in another study, only stable patients were included whereas our population included both stable patients and those with exacerbations. ${ }^{36}$ Another study also reporting higher rates of mild COPD in a GP population was based on electronic records and thus a complete set of all COPD patients having lung function data was available, but a COPD diagnosis was not confirmed. ${ }^{37}$ Our study showed some inter-country variation with regard to COPD severity distribution, but this was small and not statistically significant. Other studies have not tested such between-country comparisons, ${ }^{35-37}$ but we believe that the size of our sample make it sufficiently representative of a PCP population of COPD patients across Europe.

\section{Implications for future research policy and practice}

This study design could not test the added benefit of HRQL assessment in primary care. It has shown that PCPs appear to detect health status impairment in their patients quite well but, since the assessments were made independently of any knowledge of the patients' HRQL scores, it is not possible to ascribe the quality of the PCPs' assessments to the use of these instruments. A different study design would be needed to test this hypothesis. However, a major benefit of the study design is that the PCPs' assessments should not have been biased by factors that were different from those that they use routinely, except for the MRC dyspnoea scale which might be used less systematically in their usual practice.

\section{Conclusions}

This large survey in primary care across Europe has shown that HRQL is markedly impaired across all severities of COPD. PCPs successfully graded COPD severity clinically, and appeared to have greater discriminative power for assessing severity in COPD than FEV ${ }_{1}$-based staging. Their more holistic approach appeared to reflect the patients' HRQL rating which should, however, be assessed for a comprehensive evaluation. These data were consistent across five European countries and may be applicable more widely.

\section{Handling editor David Bellamy}

\section{Statistical review Gopal Netuveli}

Acknowledgements The authors would like to acknowledge editorial support in the form of development of the manuscript first draft, assembling tables and figures, collating author comments, copyediting and referencing which was provided by Kate Hollingworth of Continuous Improvement Ltd, funded by GlaxoSmithKline (GSK). A full review of all drafts with comprehensive input and editing was provided by all authors and therefore $\mathrm{KH}$ is not included as an author on this paper.

Conflicts of interest PWJ has received fees from pharmaceutical companies including GSK for speaking at meetings, participating in advisory board meetings, and to support research. GB has received honoraria for lectures and has participated in advisory board meetings for various pharmaceutical companies including GSK. PK has received lecture fees and participated in advisory boards and sponsored clinical trials for various pharmaceutical companies including GSK. MLL has served on advisory boards and received sponsorship, lecture fees and research funds from various pharmaceutical companies including GSK. JJSC has received lecture fees and research support from various pharmaceutical companies including GSK. LA and NB are employees of GSK. RWDN, TP and TvdM have no conflicts of interest to declare. Contributorship PWJ: Study concept and design (member of Study Advisory Committee); interpretation of results; drafting, review and approval of manuscript. GB, RWN, MF, PK, MLL, TP, JJSC, TvdM: Study concept and design (member of Study Advisory Committee); interpretation of results; review and approval of manuscript. LA: Study concept and design; interpretation of results; drafting, review and approval of manuscript. NB: Study concept and design; statistical analysis; interpretation of results; drafting, review and approval of manuscript.

Funding Funding for this study was provided by GSK (study number 111749). Editorial support provided by Kate Hollingworth was funded by GSK.

\section{References}

1. Chapman KR, Mannino DM, Soriano JB, et al. Epidemiology and costs of chronic obstructive pulmonary disease. Eur Respir J 2006;27:188-207. http://dx.doi.org/10.1183/09031936.06.00024505

2. The Global Initiative for Chronic Obstructive Lung disease (GOLD) revised 2009; wuw.goldcopd.com.

3. Bellamy D, Bouchard J, Henrichsen S, et al. International Primary Care Respiratory Group (IPCRG) guidelines: management of chronic obstructive pulmonary disease (COPD). Prim Care Respir J 2006;15:48-57.

http://dx.doi.org/10.1016/j.pcrj.2005.11.003

4. Sobradillo-Pena V, Miravitlles M, Gabriel R, et al. Geographic variations in prevalence and underdiagnosis of COPD: results of the IBERPOC multicentre epidemiological study. Chest 2000;118:981-9. http://dx.doi.org/10.1378/chest.118.4.981

5. Frank TL, Hazell ML, Linehan MF, Morris JA, Frank PI. The estimated prevalence of chronic obstructive pulmonary disease in a general practice population. Prim Care Respir J 2007;16:169-73. http://dx.doi.org/10.3132/pcrj.2007.00028

6. Fukuchi $Y$, Nishimura $M$, Ichinose $M$, et al. COPD in Japan: the Nippon COPD epidemiology study. Respirology 2004;9:458-65 http://dx.doi.org/10.1111/j.1440-1843.2004.00637.x

7. Stang P, Lydick E, Silberman C, Kempel A, Keating ET. The prevalence of COPD: using smoking rates to estimate disease frequency in the general population. Chest 2000;117(Suppl 2):354S-9S. http://dx.doi.org/10.1378/chest.117.5_suppl_2.354S

8. National Collaborating Centre for Chronic Conditions. Chronic obstructive pulmonary disease: national clinical guideline on management of chronic obstructive pulmonary disease in adults in primary and secondary care. Thorax 2004;59(Suppl 1):181-72

9. Celli BR, MacNee W, Agusti A, et al. Standards for the diagnosis and treatment of patients with COPD: a summary of the ATS/ERS position paper. Eur Respir $J$ 2004;23:932-46. http://dx.doi.org/10.1183/09031936.04.00014304

10. Buist S. COPD: a common disease that is preventable and treatable. Prim Care Respir J 2006;15:7-9. http://dx.doi.org/10.1016/j.pcrj.2005.12.004

11. Cazzola M, MacNee W, Martinez FJ, et al. on behalf of the American Thoracic Society/European Respiratory Society Task Force on outcomes of COPD. Outcomes of COPD pharmacological trials: from lung function to biomarkers. Eur Respir J 2008;31:416-69. http://dx.doi.org/10.1183/09031936.00099306

12. Hay JG, Stone P, Carter J, et al. Bronchodilator reversibility exercise performance and breathlessness in stable chronic obstructive pulmonary disease. Eur Respir $J$ 1992;5:659-64 
13. O'Donnell DE, Lam M, Webb KA. Spirometric correlates of improvement in exercise performance after anticholinergic therapy in chronic obstructive pulmonary disease. Am J Respir Crit Care Med 1999;160:542-9.

14. Gruffydd-Jones K. A national strategy for the management of chronic obstructive pulmonary disease (COPD) in England: aiming to improve the quality of care for patients. Prim Care Respir J 2008;17(Suppl 1):S1-S8 http://dx.doi.org/10.3132/pcrj.2008.00071

15. Atsou K, Chouaid C, Hejblum G. Variability of the chronic obstructive pulmonary disease key epidemiological data in Europe: systematic review. BMC Med 2011;9:7. http://dx.doi.org/10.1186/1741-7015-9-7

16. Buist AS, McBurnie MA, Vollmer WM, et al. International variation in the prevalence of COPD (the BOLD Study): a population-based prevalence study. Lancet 2007;370:741-50. http://dx.doi.org/10.1016/S0140-6736(07)61377-4

17. Menezes AM, Perez-Padilla R, Jardim JR, et al. PLATINO team: Chronic obstructive pulmonary disease in five Latin American cities (the PLATINO study): a prevalence study. Lancet 2005;366:1875-81. http://dx.doi.org/10.1016/S0140-6736(05)67632-5

18. Jones PW, Brusselle G, Dal Negro RW, et al. Health-related quality of life in patients by COPD severity within primary care in Europe. Respir Med 2011;1:57-66. http://dx.doi.org/10.1016/j.rmed.2010.09.004

19. Meguro M, Barley EA, Spencer S, Jones PW. Development and validation of an improved COPD specific version of the St. George Respiratory Questionnaire. Chest 2007;132:456-63. http://dx.doi.org/10.1378/chest.06-0702

20. Ware JE, Kosinski M, Keller SD. A 12-item short form health survey: construction of scales and preliminary tests of reliability and validity. Med Care 1996;34:220-33. http://dx.doi.org/10.1097/00005650-199603000-00003

21. Jones PW, Harding G, Berry P, Wiklund I, Chen W-H, Kline Leidy N. Development and first validation of the COPD Assessment Test. Eur Respir J 2009;34:648-54. http://dx.doi.org/10.1183/09031936.00102509

22. Webster K., Odom L, Peterman A, Lent L, Cella D. The Functional Assessment of Chronic Illness Therapy (FACIT) measurement system: validation of version 4 of the core questionnaire. Qual Life Res 1999;8(7):604

23. Bestall JC, Paul EA, Garrod R, Garnham R, Jones PW, Wedzicha JA. Usefulness of the Medical Research Council (MRC) dyspnoea scale as a measure of disability in patients with chronic obstructive pulmonary disease. Thorax 1999;54:581-6. http://dx.doi.org/10.1136/thx.54.7.581

24. Jones PW, Brusselle G, Dal Negro RW, et al. Properties of the COPD assessment test in a cross-sectional European study. Eur Respir J 2011;38:29-35. http://dx.doi.org/10.1183/09031936.00177210

25. Miravitlles M, Soriano JB, García-Río F, et al. Prevalence of COPD in Spain: impact of undiagnosed COPD on quality of life and daily life activities. Thorax 2009;64:863-8 http://dx.doi.org/10.1136/thx.2009.115725.

26. van Schayck CP, Chavannes NH. Detection of asthma and chronic obstructive pulmonary disease in primary care. Eur Respir J 2003;21:16s-22s. http://dx.doi.org/10.1183/09031936.03.00040403

27. Norrhall MF, Nilsfelt A, Varas $\mathrm{E}$, et al. A feasible lifestyle program for early intervention in patients with chronic obstructive pulmonary disease (COPD): a pilot study in primary care. Prim Care Respir J 2009;18(4):306-12. http://dx.doi.org/10.4104/pcrj.2009.00041

28. Bednarek M, Gorecka D, Wielgomas J, et al. Smokers with airway obstruction are more likely to quit smoking. Thorax 2006;61:869-73. http://dx.doi.org/10.1136/thx.2006.059071

29. Wilt TJ, Niewoehner D, Kim C, et al. Use of Spirometry for Case Finding, Diagnosis, and Management of Chronic Obstructive Pulmonary Disease (COPD). Summary, Evidence Report/Technology Assessment: Number 121. AHRQ Publication Number 05-E017-1, August 2005. Agency for Healthcare Research and Quality, Rockville, MD. http://www.ahrq.gov/clinic/epcsums/spirosum.htm

30. Puhan MA, Vollenweider D, Latsgang T, Steurer J, Steurer-Stey C. Exacerbations of chronic obstructive pulmonary disease: when are antibiotics indicated? A systematic review. Respir Res 2007;8:30. http://dx.doi.org/10.1186/1465-9921-8-30

31. Quon BS, Gan WQ, Sin DD. Contemporary management of acute exacerbations of COPD. A systematic review and metaanalysis. Chest 2008;133:756-66. http://dx.doi.org/10.1378/chest.07-1207

32. Ferrer M, Villasante $C$, Alonso J, et al. Interpretation of quality of life scores from the St George's Respiratory Questionnaire. Eur Respir J 2002;19:405-13.

33. Carrasco-Garrido P, de Miguel-Diez J, Rejas-Gutierrez J, et al. Negative impact of chronic obstructive pulmonary disease on the health-related quality of life of patients: results of the EPIDEPOC study. Health Qual Life Outcomes 2006;4:31.

34. Carrasco-Garrido P, de Miguel-Diez J, Rejas-Gutierrez J, et al. Characteristics of chronic obstructive pulmonary disease in Spain from a gender perspective. BMC Pulm Med 2009;9:2. http://dx.doi.org/10.1186/1471-2466-9-2

35. Bednarek M, Maciejewski J, Wozniak M, Kuca P, Zielinski J. Prevalence, severity and underdiagnosis of COPD in the primary care setting. Thorax 2008;63:402-07. http://dx.doi.org/10.1136/thx.2007.085456

36. Izquierdo JL, Barcina C, Jimenez J, Munoz M, Leal M. Study of the burden on patients with chronic obstructive pulmonary disease. Int J Clin Pract 2009;63:87-97. http://dx.doi.org/10.1111/j.1742-1241.2008.01936.x

37. Hoogendoorn M, Feenstra TL, Schermer TR, Hesselink AE, Rutten-van Molken MP. Severity distribution of chronic obstructive pulmonary disease (COPD) in Dutch general practice. Respir Med 2006;100:83-6. http://dx.doi.org/10.1016/j.rmed.2005.04.004 